Personalidade Acadêmica Homenageada:

Augustus B. Cochran III (Agnes Scott College)

\title{
A VIDA NAS RUAS E O IMPASSE DOS RECURSOS HÍDRICOS: 0 ENDEREÇO DESCONHECIDO DO LÍQUIDO VITAL
}

\section{LIFE ON THE STREETS AND THE IMPASSMENT OF WATER RESOURCES: THE UNKNOWN ADDRESS OF VITAL NET}

\section{GIOVANNA RODRIGUES ASSIS}

Graduanda em Direito, modalidade Integral, pela Escola Superior Dom Hélder Câmara. Belo Horizonte - MG E-mail: giovannarodriguesa@hotmail.com

\section{RESUMO}

O tema-problema da pesquisa que se pretende desenvolver é o impasse do acesso aos recursos hídricos pelas pessoas em situação de rua. Nos últimos anos, o direito à água surge como um tema de extrema relevância nos debates sobre os direitos fundamentais, em razão da essencialidade dos recursos hídricos em todos os aspectos da vida humana. Desse modo, a precariedade e falta de qualidade dos sistemas hídricos que o Estado dispõe para as pessoas em situação de rua, refletem em diversas instâncias da vida desse grupo, colocando-os em um panorama em que os seus direitos fundamentais são frequentemente violados, repercutindo de forma extremamente negativa na vida desses indivíduos, que perdem a sua qualidade de vida, a sua inclusão social e, até mesmo, o seu direito a ter direitos. Tendo como ponto de partida esse fato, o problema objeto da investigação científica proposta se baseia na investigação da importância do acesso aos recursos hídricos na efetivação dos Direitos Humanos das pessoas em situação de rua. A partir das reflexões preliminares sobre o tema, é possível afirmar inicialmente que o direito à água é um fator essencial para a preservação da vida e 


\section{Personalidade Acadêmica Homenageada:}

\section{Augustus B. Cochran III (Agnes Scott College)}

da dignidade humana, princípios previstos na Declaração Universal dos Direitos Humanos. Desse modo, garantir um acesso efetivo à água para a população em situação de rua, é atuar na construção de um espaço urbano mais democrático em que as necessidades fundamentais de todos os indivíduos são respeitadas. O objetivo geral do trabalho é analisar a influência exercida pelo sistema hídrico que a população em situação de rua dispõe na realidade vivida por esse grupo e na garantia dos seus direitos fundamentais. A pesquisa que se propõe pertence à vertente metodológica jurídico-sociológica. No tocante ao tipo de investigação, foi escolhido, na classificação de Witker (1985) e Gustin (2010), o tipo jurídico-projetivo. O raciocínio desenvolvido na pesquisa será predominantemente dedutivo. De acordo com a técnica de análise de conteúdo, afirma-se que trata de uma pesquisa teórica, o que será possível a partir da análise de conteúdo dos textos doutrinários, normas e demais dados colhidos na pesquisa. Como conclusão parcial do trabalho, pode-se afirmar que as políticas públicas que o Estado dispõe, direcionadas a esse grupo vulnerável, não são capazes de suprir e efetivar as necessidades e os direitos da pessoa humana em situação de rua. Ademais, a falta de recursos hídricos para higiene e consumo faz com que esses indivíduos desenvolvam patologias e estejam sujeitos à estigmas e discriminações sociais constantes, fazendo com que uma população que já se encontra marginalizada tenha os seus direitos mais básicos negados, fato que dificulta a reintegração desse grupo na sociedade. Desse modo, observa-se que apesar de constituírem um grupo minoritário, é evidenciado que as pessoas em situação de rua constituem uma parte considerável da população brasileira. Ademais, mesmo em grande número, são indivíduos cujo o acesso aos mais básicos direitos, como os direitos aos recursos hídricos, Ihes é negado, em resposta a uma imagem que carregam em função da sua trajetória de rua. A partir desse cenário apresentado, torna-se, portanto, de extrema importância a realização dessa pesquisa para reconhecer mais a fundo os impactos causados pela precariedade do acesso aos recursos hídricos na vida dos moradores de rua e a influência que esse fator exerce na perpetuação desse grupo minoritário em um quadro de exclusão social e violação constante de direitos em que esses indivíduos se inserem. 
Personalidade Acadêmica Homenageada:

Augustus B. Cochran III (Agnes Scott College)

PALAVRA-CHAVE: Direitos Humanos; Direito aos Recursos Hídricos; Pessoas em situação de rua.

\section{REFERÊNCIAS}

GUSTIN, Miracy Barbosa de Sousa; DIAS, Maria Tereza Fonseca. (Re)pensando a pesquisa jurídica: teoria e prática. 3ª ed. Belo Horizonte: Del Rey, 2010.

WITKER, Jorge. Como elaborar uma tesis en derecho: pautas metodológicas y técnicas para el estudiante o investigador del derecho. Madrid: Civitas, 1985.

CASTRO, João Marcos Adede y Castro. Água: um direito humano fundamental. Porto Alegre: Núria Fabris Editora, 2008.

GRINOVER, Ada Pellegrini et al. Direitos Fundamentais das Pessoas em Situação de Rua. Belo Horizonte: D’Plácido Editora, 2014.

GOFFMAN, Erving. Estigma: notas sobre a manipulação da identidade deteriorada. Rio de Janeiro: Guanabara Koogan, 1988.

SOUZA, Felipe. Portal BBC News Brasil. A saga dos moradores de rua em São Paulo por um copo d'água. 15 agosto 2018. Disponível em: https://www.bbc.com/portuguese/brasil-45088766. Acesso em: 28 abril 2019.

Conselho Nacional De Segurança Alimentar E Nutricional. Portal Planalto. Direito Humano à Água. 16 dez 2014. Disponível em: http://www4.planalto.gov.br/consea/comunicacao/artigos/2014/direito-humano-aagua. Acesso em: 26 abr 2019.

RAIOL, Raimundo Wilson Gama; NONATO, Domingos do Nascimento. Mais Vulnerabilizadas À Violência Urbana: Pessoas Em Situação De Rua E A Suposta Segurança Pública. Revista Jurídica UNICURITIBA, Curitiba, v.4, n.53,p.633-658, out./dez. $2018 . \quad$ Disponível em: http://revista.unicuritiba.edu.br/index.php/RevJur/article/view/3258 Acesso em: 20 maio 2019. 